\title{
Cadaveric Assessment of Synthetic Mid-Urethral Sling Placement
}

\author{
Scott Serels \\ Bladder Control Center of Norwalk, Norwalk CT, USA \\ E-mail:scottserels@hotmail.com \\ Received March 5, 2011; revised April 25, 2011; accepted May 5, 2011
}

\begin{abstract}
Purpose: To determine if 3 types of mid-urethral synthetic slings are visually the same. Materials and Methods: A retropubic, obturator, and single incision sling was individually placed in three cadavers. Tension was set using a spacer (obturator and retropubic). Single incision sling (SIS) tension was set by visual inspection. Thirty physicians were asked to determine placement method, tension, and location of the 3 slings. Results: Physicians were composed of 5 urologists, 7 urogynecologist, and 18 general gynecologists, with an average of 53 slings performed per year. Conclusions: This study showed that after placement of a sling it is hard to tell how the sling was placed and that most physicians felt the SIS was tensioned the best and most likely at the mid-urethra.

\begin{tabular}{lccc}
\hline & Retropubic & Obturator & SIS \\
\hline \% correctly identified sling & $40 \%$ & $43 \%$ & $23 \%$ \\
$\%$ thought tension was just right & $33 \%$ & $47 \%$ & $73 \%$ \\
\% thought sling was at mid-urethra & $50 \%$ & $67 \%$ & $83 \%$ \\
\hline
\end{tabular}
\end{abstract}

Keywords: Stress Incontinence, Surgical Correction of Incontinence, Single Incision Slings

\section{Introduction}

Urinary incontinence is a common problem in adult women, with a prevalence of approximately 35\% [1]. Stress urinary incontinence (SUI), the most common form of urinary incontinence in women, is an involuntary loss of urine that occurs during physical activity, such as coughing, sneezing, laughing, or exercise. Treatment options for SUI in women are designed to prevent the involuntary loss of urine from the urethra during increases in intra-abdominal pressure. Nonsurgical therapies include behavioral therapy (e.g. bladder training, fluid and dietary modification) and limited drug therapy.

Surgical therapy for this condition has existed for over 100 years. The suburethral sling was first described in 1907 by von Giordano, and consisted of placing autologous tissue underneath the bladder neck and suspending it superiorly. Since then, over 200 different surgical procedures have been described. Sling material has also evolved from autologous fascia lata, muscle, and rectus fascia to synthetic material. The majority of midurethral slings now available use type I polypropylene mesh. The development of the mid-urethral slings and corresponding placement methodologies have evolved to improve efficacy, safety, cost-effectiveness, and to minimize invasiveness. Currently, the three main approaches to placement of synthetic mid urethral sling include retropubic, transobturator, and the single incision mini sling.

The Integral Theory of Female Urinary Incontinence by Ulmsten and Petros in the early 1990's challenged our understanding of incontinence significantly and led to the market introduction of the minimally invasive retropubic midurethral sling known as tension-free vaginal tape (TVT) [2]. The TVT procedure initiated in 1996 revolutionized the surgical management of female SUI in terms of its efficacy and minimal invasiveness. Although $80 \%$ - 89\% cure rates, with durable cure rates up to 5 years post-procedure, have been reported, blind passage through the retropubic space poses considerable risks. $[3,4]$ Potential complications include bowel injury, bladder injury, major vascular injury, and nerve injury. Bladder perforation in retropubic slings is a common complication with a recent meta-analysis reporting rates of 3.2\%, [5] 
and rates up to $15 \%$ have also been reported in at least one multicenter study [6]. Bowel and vascular injuries have also been reported, though less frequently than bladder perforations, but are more serious and have resulted in patient deaths.

The transobturator approach was first described by Delorme in 2001 [7]. The major advantage of the transobturator approach is the avoidance of the retropubic space, decreasing complications such as bladder and bowel perforation, and major vascular injury. Bladder perforation using the transobturator approach have reported rates as low as $0 \%$, considerably less than those reported for the retropubic procedure [5]. Recent studies report that the transobturator method provides intermediate-term efficacy results that are comparable to the retropubic method with a reduction in major complication risks [8-10]. As a result, the transobturator approach has increased in popularity for midurethral sling placement in many centers due to its efficacy and low morbidity.

In keeping with the trend of improving SUI treatment options (less invasive, more efficacious, safer, improved recovery), the single-incision method has recently been introduced. Single-incision slings provide the latest advance in midurethral tensionless sling technology and require only one small vaginal incision placed beneath the urethra. Proposed advantages of the single-incision method over the retropubic and transobturator are less postoperative pain and decreased incidence of complications [11]. Currently however, there is minimal data available on the long-term efficacy and safety of the single-incision method [12].

Our experience indicates that many physicians are hesitant to use the single-incision method as they think the anchoring results in tensioning that is too tight. The purpose of the current study was to determine if different mid-urethral synthetic sling placements were visually similar regardless of the placement methods, anchor sites, and tension methods. We also evaluated which sling placement was tensioned most correctly and was most likely positioned at the mid-urethra. The impetus for this study was the realization that visually all slings, regardless of their approach for placement, look fairly similar after being placed in live patients although the means of placement may be different.

\section{Materials and Methods}

Three, fresh female cadavers, with mid-urethal slings placed by either the retropubic, transobturator, or single incision method, were used for this investigation. All three slings used Advantage Mesh from Boston Scientific, USA. Incisions for each of the 3 placement methods were made on each cadaver so the method of placement could not be determined by incisions alone. A single surgeon performed all of the cadaveric sling placements.
This particular surgeon performs over 200 slings each year. In his own practice, he performed, at the time of this study in his live patient population, approximately $15 \%$ of his slings by the suprapubic approach, $50 \%$ by the obturator approach, and 35\% of his slings by the single incision approach.

The retropubic sling procedure was performed by making a $15 \mathrm{~mm}$ sagittal incision in the vaginal wall, at the level of the mid-urethra, followed by a periurethral dissection plane which was extended laterally toward the ischiopubic rami. Two stab incisions were made in the suprapubic region at the upper rim of the pubic bone, 2 $\mathrm{cm}$ lateral from the midline. Then, a trocar was placed within the periurethral tunnel with the tip of the device between the index finger and the lower rim of the pubic ramus. The device was pushed upwards with controlled pressure to exit the suprapubic incision, keeping the tip of the tunneler in close contact with the pubic bone. The procedure was repeated on the contralateral side (Figure 1(a)). The synthetic mesh was transferred from the suburethral incision to the skin incisions on each side followed by tension-free adjustment using a 12 Hagar dilator as a spacer (Figure 2).

The transobturator technique used was based on Delorme's description. 5 An anterior, vertical $15 \mathrm{~mm}$ vaginal incision was made at a point approximately $1 \mathrm{~cm}$ below the urethral meatus. Dissection was then made laterally toward the ischiopubic ramus. The entry point was made at the junction of the adductor longus tendon and inferior pubic ramus. The tip of the trocar was introduced through this incision, initially in a direction perpendicular to the cadaver, and then oriented upward and inward in an oblique direction to reach the index finger introduced in the periurethral space once the obturator muscle and membrane had been punctured. The introducer was exteriorized from the suburethral incision, and the tape or the synthetic mesh was transferred from this site to the skin incision (Figure 1(b)). The same procedure was performed on the contra-lateral side, and then tension-free adjustment was set using a 12 Hagar dilator as a spacer (Figure 2).

For the single-incision method, a 1 to $1.5 \mathrm{~cm}$ midurethral anterior vaginal wall incision was made. Dissection was then made up to the inferior pubic ramus on either side of the urethra. The single incision sling was placed into the obturator internus muscle using the introducer and repeated on both sides (Figure 1(c)). The tension of the single incision sling was set so the sling lay against the urethra such that pillowing of the periurethral tissues were observed through the pores of the sling.

After placement of each sling, blinding incisions were completed and 30 gynecologists and general urologists of different specializations visually inspected the sling 


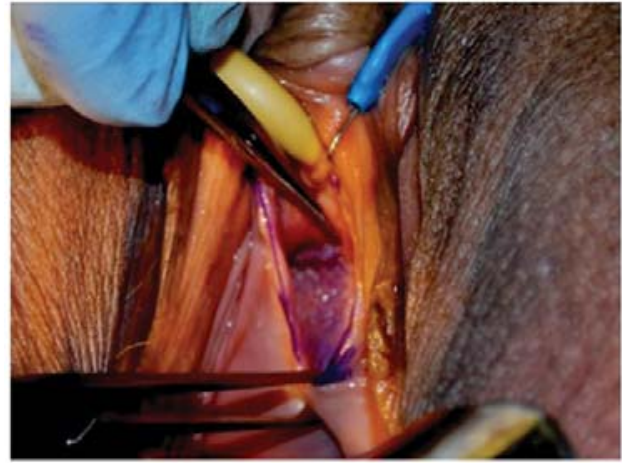

(a)

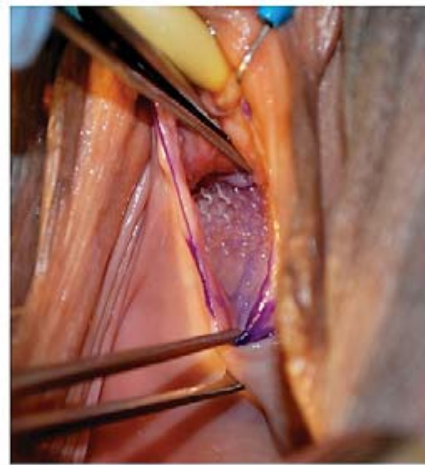

(b)

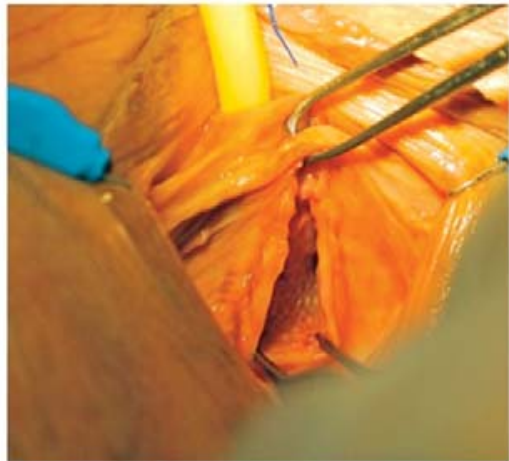

(c)

Figure 1. Placement of mid-urethal slings to alleviate stress urinary incontinence using the (a) retropubic; (b) transobturator; (c) single incision techniques.

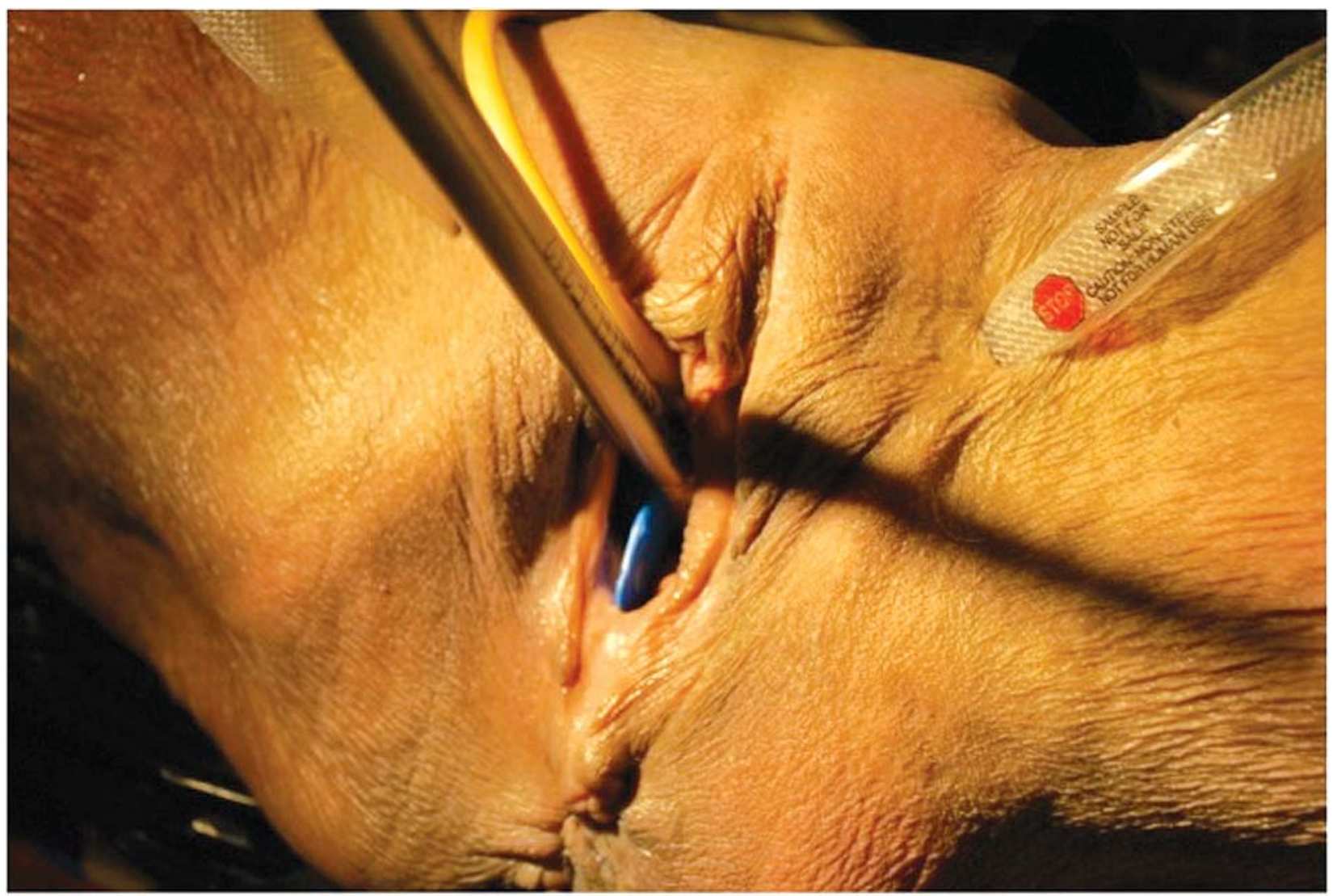

Figure 2. Tension-free adjustment for the retropubic and transobturator techniques was set using a 12 Hagar dilator as a spacer.

placements. These were experienced surgeons who used their own experience and knowledge to give their opinion of the sling placement. This study was a visual assessment. The physicians were not able to palpate the slings. The rationale for not allowing patients to touch the slings was that if people pulled on the slings then it may change their position and/or allow people to figure out how they were placed.

Each physician was asked to respond to 3 questions:
1) How was the sling placed?
a. retropubic
b. obturator
c. single incision

2) Is the sling the right tension?
a. too tight
b. just right
c. too loose

3) Is the sling located at the mid-urethra or bladder neck? 


\section{Results}

\subsection{Physician Specialization and Characteristics}

Reviewing physicians were gynecolgists or general urologists of varying specializations. The average number of slings performed each year was 53, with obturator and retropubic being the most favoured sling types (Table 1). Most physicians preferred the obturator or retropubic slings. Markedly fewer physicians used all three techniques or a combination of obturator plus retropubic/single incision techniques.

\subsection{Physician Review}

Less than half of the physicians (40\%, 43\%, 23\%; Figure 3) were able to correctly identify the sling placement used in each cadaver, and were least likely to identify the single incision sling placement (23\%). The single incision sling, in which the tension was not set with a spacer, was thought to have the most appropriate tension (73\% tension just right versus 33\% retropubic and $47 \%$ obturator). Furthermore, the single incision sling was identified more often (83\%) as placed at the mid-urethra, compared to the retropubic (50\%) and the obturator (67\%) (Figure 3).

\section{Discussion}

Urinary incontinence is a common problem in adult women, with SUI the most common form. Treatment options for SUI in women are designed to prevent the involuntary loss of urine during increases in intraabdominal pressure.

The retropubic sling has reported success rates of $80 \%$ - $89 \%$, but requires blind passage through the retropubic space, posing risks for bowel injury, bladder injury, major vascular injury, and nerve injury [3,4].The tran-

Table 1. Backgroud Information regarding the surgeons that participated in this study.

\begin{tabular}{|c|c|}
\hline Characteristics & $\begin{array}{c}\text { Reviewing Physicans } \\
\mathbf{N}=\mathbf{3 0}\end{array}$ \\
\hline \multicolumn{2}{|l|}{ Specialty, n (\%) } \\
\hline General Urology & $5(17)$ \\
\hline Gynecology & $18(60)$ \\
\hline Urogynecology & $7(23)$ \\
\hline \multicolumn{2}{|l|}{ Preferred Sling Type, n (\%) } \\
\hline Retropubic & $11(37)$ \\
\hline Transobturator & $13(43)$ \\
\hline Single Incision & $2(7)$ \\
\hline Retropubic and Transobturator & $1(3)$ \\
\hline Retropubic and Single incision & $1(3)$ \\
\hline All Slings & $1(3)$ \\
\hline No Preference & $1(3)$ \\
\hline \multicolumn{2}{|l|}{ Number of Slings Placed per Year } \\
\hline Mean & 53 \\
\hline Min & 0 \\
\hline Max & 200 \\
\hline
\end{tabular}

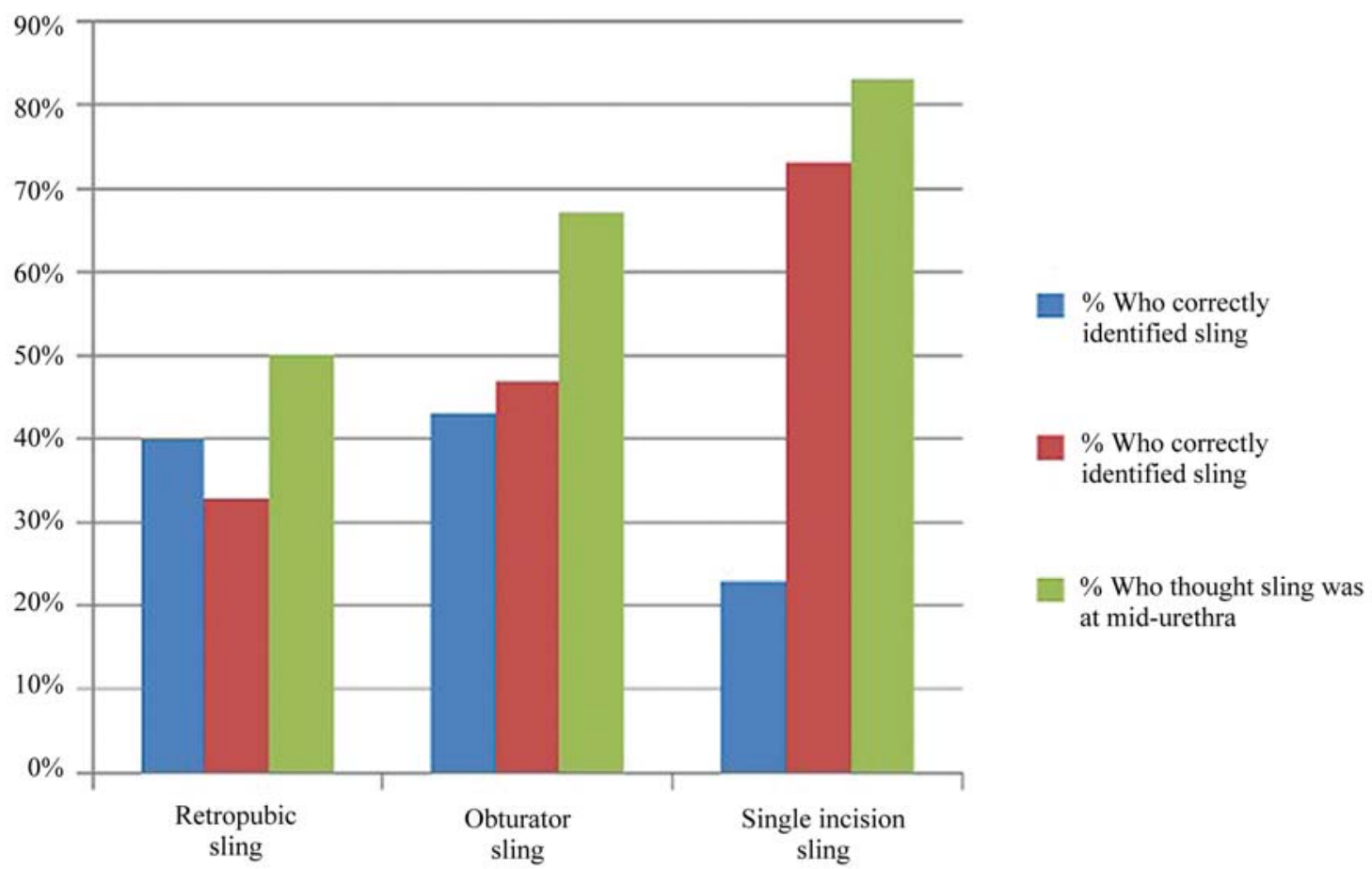

Figure 3. Physician assessment of sling technique, tension, and placement. 
sobturator, by contrast, avoids the retropubic space, decreasing complications such as bladder and bowel injuries and is as efficacious as the retropubic method with a reduction in adverse events [8-10]. Single incision slings provide the latest advance in midurethral tensionless sling technology and require only one small vaginal incision placed beneath the urethra thereby potentially reducing post-operative pain and risk of complications. However, minimal data are currently available on the long-term efficacy and safety of the single-incision method.

Our experience has been that most physicians view the single incision sling as being different than the retropubic or transobturator slings. Furthermore, physicians often describe the single-incision as a "tight" sling. This association of "tight" with the single-incision sling is based primarily on perceived placement methodology, and not on actual tensioning tests. For example, the tension of the single-incision sling is achieved by pushing the sling into tissue rather than pulling up on it as is done for the retropubic and transobturator slings. When the coverings are taken off and any spacing devices are removed from the multi-incision slings, there is further retraction that occurs. Thus, the initial placement of the multi-incision sling changes and the sling tightens a small amount. In contrast, placement of the single incision sling does not change, and the site of the sling during tensioning is where it remains. As a result, the single-incision sling may seem slightly tighter on initial placement, but appears the same as the others when the sling is in its final position.

The purpose of this study was to determine if the single-incision sling looks different than the other commonly used retropubic and obturator slings, and to determine which of the three slings was identified by trained physicians as being most correctly tensioned at the mid urethra. The results showed that well-trained, experienced incontinence surgeons could not visually differentiate between sling placement methodologies. Less than half of the physicians (40\%, 43\%, 23\%) were able to correctly identify the sling placement used, and were least likely to be able to identify a single-incision sling placement (23\% correctly identified).

Furthermore, the results showed that the single incision sling was identified as having the most correct tension (73\% tension just right versus 33\% retropubic and $47 \%$ obturator) and the most correct mid-urethral positioning (83\% versus 50\%retropubic and 67\% obturator). Of note, 6 physicians who were highly experienced in sling placement (> 100 procedures/year each). There were no clear trends in the ability to appropriately identify the sling placement method used based on physician experience. Taken together, these data seem to initially dispel some of the previously held misconceptions of how a single-incision sling differs from multi-incision sling procedures and indicate that the biases toward the single incision sling typically voiced by practicing physicians seem to be rooted in preconceived misconceptions and not on actual results, regardless of experience or specialty.

Conclusions: This study showed that after placement of a midurethral synthetic sling it is difficult to determine the placement method used and that most physicians assessed the single-incision sling as tensioned most appropriately and most likely positioned at the mid-urethra.

\section{Acknowledgements}

This study was supported by an unrestricted grant from Boston Scientific.

\section{References}

[1] S. Hunskaar, G. Lose, D. Sykes, et al., "The Prevalence of Urinary Incontinence in Women in Four European Countries,” Journal of the British Association of Urological Surgeons, Vol. 93, 2004, pp. 324-330.

[2] P.E Petros and U. Ulmsten, "An Integral Theory of Female Urinary Incontinence," Acta Obstetricia et Gynecologica Scandinavica, Supplement 153, Vol. 69, 1990, pp. 7-31.

[3] C. G. Nilsson, N. Kuuva, C. Falconer, et al., "Long-Term Results of the Tension-Free Vaginal Tape (TVT) Procedure for Surgical Treatment of Female Stress Urinary Incontinence,” International Urogynecology Journal and Pelvic Floor Dysfunction, Supplement 2, Vol. 12, 2001, pp. S5-S8. doi:10.1007/s001920170003

[4] K. L. Ward and P. Hilton, "UK and Ireland TVT Trial Group. Tension-Free Vaginal Tape Versus Colposuspension for Primary Urodynamic Stress Incontinence: 5-Year Follow Up,” BJOG, Vol. 115, No. 2, 2008, pp. 226-233. doi:10.1111/j.1471-0528.2007.01548.x

[5] V. W. Sung, M. D. Schleinitz, C. R. Rardin, et al., "Comparison of Retropubic versus Transobturator Approach to Midurethral Slings: A Systematic Review and MetaAnalysis," American Journal of Obstetrics and Gynecology, Vol. 197, No. 1, 2007, pp. 3-11. doi:10.1016/j.ajog.2006.09.025

[6] A. C. Wang, "The Techniques of Trocar Insertion and Intraoperative Urethrocystoscopy in Tension-Free Vaginal Taping: An Experience of 600 Cases," Acta Obstetricia et Gynecologica Scandinavica, Vol. 83, No. 3, 2004, pp. 293-298.

[7] E. Delorme, “Transobturator Urethral Suspension: MiniInvasive Procedure in the Treatment of Stress Urinary Incontinence in Women [in French],” Prog Urol, Vol. 11, No. 6, 2001, pp. 1306-1313. 
[8] W. Al-Singary, I. S. Shergill, S. E. Allen, et al., "Transobturator Tape for Incontinence: A 3-Year Follow-Up,” Urologia Internationalis, Vol. 78, No. 3, 2007, pp. 198-201. doi:10.1159/000099337

[9] P. M. Latthe, R. Foon and P. Toozs-Hobson, "Transobturator and Retropubic Tape Procedures in Stress Urinary Incontinence: A Systematic Review and Meta-Analysis of Effectiveness and Complications," BJOG, Vol. 114, No. 5, 2007, pp. 522-531. doi:10.1111/j.1471-0528.2007.01268.x

[10] P. Grise, S. Droupy, C. Saussine, et al., "Transobturator Tape Sling for Female Stress Incontinence with Polypropy-Lene Tape and Outside-In Procedure: Prospective Study with 1 Year of Minimal Follow-Up and Review of Transob-Turator Tape Sling,” Urology, Vol. 68, 2006, pp. 759-763.

doi:10.1016/j.urology.2006.04.020

[11] R. Moore, T. Erickson, S. Serels, et al., "Retrospective Review of Early Experience Using the AMS MiniArc Single Incision Sling," Journal of Minimally Invasive Gynecology, Vol. 14, No. 6, 2007, pp. S129-130 (Abst.357).

[12] R. D. Moore, S. R. Serels and G. W. Davila, "Minimally Invasive Treatment for Female Stress Urinary Incontinence,” Expert Review of Obstetrics \& Gynecology, Vol. 3, No. 2, 2008, pp. 257-272. doi:10.1586/17474108.3.2.257 